\title{
S sciendo
}

DOI: $10.2478 /$ rjp-2020-0014

Rom J Psychoanal 2020, 13(2):7-12

Rom J Psychoanal

\section{EDITORIAL}

Georgiana Dobrescu ${ }^{1}$

The articles presented in the $2 / 2020$ issue of the Romanian Journal of Psychoanalysis continue the theme of THE SECRET, begun in this year's first issue.

This issue appears in a period that is entirely particular for us all, in the midst of a Covid19 pandemic. In the current context, it seems to me that the theme of the secret is not at all accidental. The secret, as something hidden, unknown, mysterious, wants to be unveiled and brought to light in order to better understand, to clarify and find new solutions for a given situation. The pandemic started at the beginning of this year, with many unknown and mysterious aspects. Now, as the end of the year approaches, we already know many of this virus's secrets and we are rapidly coming closer to finding a vaccine.

On another scale of reporting, we hope that the articles in this issue of the journal will reveal different secrets that we all thought about at some point: family secrets, secrets of life, death, secrets related to envy and/or psychopathology that block and cleave mental functioning, maternity/femininity secrets, and many more.

\footnotetext{
${ }^{I}$ Romanian Society of Psychoanalysis; georgiana1dobrescu@yahoo.com
} 
I will begin with the article written by Rossella Valdre, titled "What if I didn't go out any more? Psychoanalytic reflections on psychic retreats in the time of Covid-19". The main general reaction to isolation includes a variety of states: panic, fear, anxiety, denial, depression, loneliness, but the author tells us about a special condition that many of us have and can develop during this time, namely "claustrophilia" or "cabin syndrome" as it was called by the Italian mass media. From 'claustrum', meaning closed space, and 'philia' love, claustrophilia, as the love for closed space, represents the inner place within ourselves where we feel protected and safe, a kind of warm and comfortable nest we retire in with pleasure. Rossella Valdre refers to several authors - Elvio Facchinelli, D. Meltzer, F. Tustin, Bollas, Steiner etc. - who see this internal space as a place of the mind, a maternal space built from the unconscious infantile fantasies of unity and reunion. Thus, another view of this experience of the Covid 19 pandemic is proposed, in which we have the possibility to be in more contact with ourselves, to think, feel and reflect.

Viviane Chetrit Vatine in her article 'From the Parents to the Child: The Ethical Dimension' proposes a subject that is always actual and that requires a continuous work from adults in the relationship with their children. The ethic dimension, meaning the responsibility for the other, has its origin in the feminine maternal aspect of any human being. Normally, in most cases, a good enough mixture between sexual life/death drives, ethic abilities and vital narcissism is maintained in the psyche of adults. There is always an asymmetrical responsibility in the parent - child relationship. Thus, the ethic dimension of parents is intertwined with the 'believing waiting' state of the child or the 'ethical exigency' state. The result of this 
interaction eventually leads to a healthy development of the child and facilitates a sense of singularity, identity and becoming of the child.

The article of René Roussillon, 'Listening to the archaic in the adult' reveals to us the way in which early infantile experiences can be better understood by the analyst within the analytic process. A part of these experiences can be symbolized, represented and expressed through language, yet other early traumatic experiences cannot be elaborated on the level of secondary processes. Après-coup processes, reformulations and new translations of early experiences can be present or not in the patients' discourse, depending on the severity of the trauma and the level of psychic development at that time. The sensibility of the analyst, his capacity to listen to the "child within the adult' is required, so that these early experiences can be deciphered and elaborated in the analytical relationship.

Daniela Luca's 'Secret of life, secret of death' underlines the importance of secrets in the intra-psychic, relational and familial life of the individual, with their traumatic impact on it, as well as its potential for processing traumatic experiences when these secrets are revealed in psychoanalysis. Kept secrets, inter/trans-generationally transmitted are exemplified by the author through clinical vignettes, once again emphasizing their impact on the psychic life of the individual.

Gabriela Romaneț, through her 'Relational architecture organised around family secrets' completes the work of Daniela Luca referring to family secrets transmitted inter/trans-generationally. The act of secrecy is an act of thought (Pierre Janet) in which someone decided what to say and what not to say, in which this person's Superego does not authorize an information to become known. The 
superego belongs to a narcissistically wounded structure that thus decided to protect itself from shame, guilt, suffering. In this way, the secret becomes a taboo, not allowing any elaboration / symbolization / knowledge / healing, an interdiction that is passed on and perpetuates trauma.

Eike Hinze, in his work 'Envy: Mortal Sin or Psychological Phenomenon to be Interpreted' proposes a different perspective over the phenomenon of envy. Freud considered 'penis envy' to be the central element of feminine psychology. Over time, this theory expired and this approach was abandoned. Melanie Klein considered 'oral envy' as playing a central role in the psychic life of the individual, an envy that is derived from the 'death instinct'. Additionally, today this approach is also questioned. So, how can we understand this complex psychic phenomenon differently? The author uses the neuropsychoanalytical perspective (Mark Solms) and the past/present unconscious described by Sandlers in order to emphasize other means of understanding envy. The careful understanding of the patient's biography and the narcissistic substratum at the base of this narration are such means.

Henrik Henkel, in his work 'Traditions of Understanding in Psychoanalysis' questions the way in which we view understanding in psychoanalysis, as the science that has always known an evolution throughout time. There are two large approaches, and the first one is the classical, Freudian one, in which psychoanalysis is understood as a reveal, an understanding of the past, an 'unmasking', a look back. The second approach is the modern one, in which understanding is the result of a dialogue that attempts the facilitation of an understanding before, the analytical relationship being seen as a 'field' where the two 
participants are 'intertwined'. The author uses the contributions of Peter Fonagy and Mary Target, of the Boston Group, as well as those of Vaikko and Riitta Tahka to support his work. So, presently, in their clinical work most analysts are both 'archeologists' and 'teleologists'.

Tatjana Pushkarova and Paolo Fonda in their work 'Ruined Lives: Some Considerations of Motherhood and Femininity in the period of repressions in Soviet Union' reveals the way in which trauma caused by totalitarian regimes is transmitted transgenerationally and the great difficulty with which it is processed and metabolized. In such societies, culture plays an important role, as a 'witness of truth', functioning as a 'container', a sort of 'second skin' that ensures the psychic survival of individuals and the preservation of their humanity.

Giuseppe Civitarese in his article 'Regression in analytic field' analyses the concept of regression from a Bionian and post-Bionian perspective - Ogden, Ferro, Civitarese.

According to Bion, patients enter analysis already regressed and they mustn't be forced to regress more than that. Using the two metaphors of Bion: the 'map' and the 'orchestra', but also the 'dreaming undreamt dreams' of Ogden and the capacity for fixating alpha elements in dream-thoughts - Ferro - the author manages to offer another perspective over the concept/phenomenon of regression.

Brînduşa Orăşanu, in her work 'Discussion on Some Notes on Fusion by Paolo Fonda' nuances the concepts of 'micro-area of fusion' and 'separation coefficient' presented by the author in her work 'Some notes on fusion', at the Conference on the Archaic held in Bucharest in 2018. 
To conclude, Alice Popescu, in her work 'Encounter with Death. The Double Suicide of Arthur Koestler and His Wife, Cynthia', explores the possible psychoanalytic reasoning behind the double-suicide of Arthut Koestler and his wife Cynthia, in 1983, in their London home.

We hope that the works presented in this issue of the Romanian Journal of Psychoanalysis provoke, inspire and delight you! Thank you! 